This is a post-peer-review, pre-copy edited version of an article published in Voluntary

Sector Review. The definitive publisher-authenticated version (Paine, A., McKay, S. and Moro,

D. (2013) 'Volunteering and employability' in Voluntary Sector Review. 4 (3) pp 355-376 (November)) is available online at: http://dx.doi.org/10.1332/204080513X13807974909

\title{
Does volunteering improve employability? Insights from the British Household Panel Survey and beyond
}

Authors: Paine, Angela Ellis; McKay, Stephen; Moro, Domenico

\begin{abstract}
:
Policy interest in the role of volunteering as a route to employment is enduring, with an assumption that links between volunteering, employability and employment are positive and straightforward. This has largely been supported by existing evidence, although there have been few longitudinal studies testing the theory. Analysing data from the British Household Panel Survey, we used multivariate techniques to explore the effects of volunteering on moves from being out of work into work; and on retention and wage progression for people in employment. We suggest that the relationship is complex: volunteering may have a positive effect on the labour market position of some individuals in some circumstances; for others it may have a negative, or no, effect. We offer some suggestions for the variations we found: the limitations of the dataset and our analysis; a limited concept of employability; and too narrow a view of volunteering and its impact.
\end{abstract}

Keywords: EMPLOYABILITY; EMPLOYMENT; RETENTION; VOLUNTEERING 


\section{Introduction}

The extent to which volunteering can enhance employability is an empirically interesting question, and a policy-relevant one. This article seeks to address it by bringing together existing evidence along with new insights from an analysis of the British Household Panel Survey.

High levels of unemployment in the UK have contributed to an on-going interest in volunteering as a route to employment. Volunteering is seen to enhance employability through offering participants the chance to develop new skills, extend networks, build CVs, try new vocations and gain experience (for example, DirectGov, 2012).

New Labour was prolific in its development of volunteering initiatives, many of which had enhancing employability as one of their goals (e.g. v, Millennium Volunteer, Volunteer Brokerage Scheme). While the Coalition government has, in general, been less enthusiastic about specific initiatives (Zimmeck and Rochester, 2011), in 2010 it launched Work Together $^{1}$ to 'encourage all unemployed people to consider volunteering as a way of improving their employment prospects while they are looking for work' (Department for Work and Pensions, 2012). The Coalition's National Citizens Service (NCS) ${ }^{2}$ also aspires in part to build skills and employability through a mix of volunteering and team building activities. The potential of volunteering to help young people gain employment has been particularly highlighted through such initiatives (see for example Davis Smith et al., 2002; Holdsworth and Quinn, 2010; Yarwood, 2005). To date, while volunteering has been encouraged and facilitated through such initiatives, UK policies have stopped short of making it a pre-requisite for benefits, or directly brokering volunteering opportunities through Jobcentres.

\footnotetext{
${ }^{1}$ Work Together is a UK-wide programme to encourage unemployed people to consider volunteering to improve their employment prospects. It is delivered by Jobcentre Plus (the executive agency which helps people access jobs and benefits), through a combination of signposting relevant volunteering opportunities or support structures, and working with volunteer-involving organisations to encourage the development of opportunities for unemployed people.

${ }^{2}$ The National Citizens Service is a scheme open to all 16-17 year olds in England, designed to build work and life skills and a more cohesive, engaged and responsible society through a combination of residential and homebased social action projects. In 2012, approximately 26,000 young people took part in the programme.
} 
These programmes and the wider policy agendas within which they fit assume that volunteering increases employability, acting as a pathway into employment. Evidence to support the effect of volunteering on employability and employment, however, remains scarce (Smith, 2010; Holdsworth and Quinn, 2010). The aim of this article is to begin to address this gap.

After reviewing the current policy landscape and the existing evidence on the link between volunteering and, this article takes a longitudinal perspective by drawing on data from the British Household Panel Survey (BHPS), 1996-2008, which included questions on both volunteering and employment over seven waves. The data is analysed using multivariate techniques. We explore the effect of volunteering primarily on the move from being out of work into work; and also on retention and progression in terms of wage rates for people in employment. As the literature and the results of our analysis of the BHPS data reveal that there is no simple answer to the question of whether volunteering enhances employability, the final part of our paper offers a set of potential explanations for the variations we find.

\section{Background}

\section{Interest in employability}

The number of unemployed people in the UK stood at 2.51 million in June 2013, an unemployment rate 7.8 per cent amongst the economically active population, 21.4 per cent among those aged 16-24 (Office for National Statistics, 2013). These figures are set against an increasingly work-focused welfare state, with emphasis placed on skills-based solutions to economic problems and labour market participation viewed as the solution to social exclusion (Hillage and Pollard, 1998). For the past decade or so we have seen an employability based approach within labour market and welfare to work policies (McQuaid and Lindsay, 2005).

The concept of employability has been variously defined. Hillage and Pollard (1998: 2) suggest that 'In simple terms, employability is about being capable of getting and keeping fulfilling work. More comprehensively, employability is the capability to move selfsufficiently within the labour market to realise potential through sustainable employment'. McQuaid and Lindsay (2005) argue that employability consists of three sets of factors: individual factors (employability skills and attributes, demographics, health and well-being, job seeking, adaptability and mobility); personal circumstances (household circumstances, 
work culture, access to resources); and, external factors (demand factors, enabling support factors).

It has been suggested that within UK policy the focus has been on the move from unemployment into employment (rather than on maintaining or enhancing employment), and on individual factors (rather than personal circumstances or external factors), with 'employability' often used as shorthand for 'the individual's employability skills' (Hillage and Pollard, 1998; see also Wilton, 2011). Underlying this emphasis on individual skills and abilities - the supply side of the equation (Peck and Theodore, 2000; McQuaid and Lindsay, 2005) - is an assumption that the relationship between employability and employment is straightforward. In unison with others, however, we question this assumption and suggest that considering only supply side interventions might be misleading. As we go on to discuss, volunteering can be seen to fit within the category of supply side interventions, seized upon by government as having the potential to add to individual factors such as employability skills and attributes, and so provide a route to employment.

\section{The volunteering fit}

According to the Citizenship Survey, in 2010-2011, 39 per cent of England's population volunteered formally (through a group or organisation) at least once during the year; 55 per cent volunteered informally (outside of group structures, on an individual basis) (CLG, 2011). Regular volunteering - on a monthly or more frequent basis - was less common, at 29 per cent and 25 per cent for informal and formal volunteering respectively. Levels of volunteering have been fairly static for the past decade (CLG, 2011).

Levels of volunteering are higher among employed people (particularly part-timers and the self-employed) than among unemployed people; they are lower among young people (16-24 year olds) than among most other age groups. Those with no qualifications are also less likely to volunteer, with the highest levels of volunteering found among those who have a degree level qualification or higher (Low et al., 2007; CLG, 2011).

The prospect of gaining career-related benefits has been identified as a motivation for volunteering. In one of the best known models of volunteer motivations (the Volunteer Functions Inventory), 'careers' was identified as one of six motivational functions served by volunteering (see for example Clary and Snyder, 1991; Clary et al, 1992). While surveys 
have typically found the careers-related motivations are less commonly reported than those related to other functions (such as 'values' and 'social'), findings vary with age and other demographics. While 7 per cent of all volunteers in one survey said they were motivated by a desire to get on in their career and 19 per cent by a desire to learn new skills, these figures rose to 27 per cent and 46 per cent respectively among 16-24 year olds (Low et al., 2007).

Several studies have found that volunteers believe that participating increases their employment prospects. More than half the volunteers in one study felt that volunteering impacted positively on their chances of finding a job (Hirst, 2001; see also Hall et al, 1998; Gay, 1998; v, 2008 for similarly findings). There is some (relatively weak) evidence to suggest that employers agree volunteering enhances employment prospects: in one survey, 90 per cent of employers said that volunteering can have a positive effect on career progression (v, 2008; see also Timebank, 2004).

Various pieces of existing evidence also give clues as to why it might be assumed that volunteering has a positive impact on employability and can act as a route to employment, given its positive influence on relevant pathways.

Human capital - the skills, knowledge and experience possessed by individuals or groups is positively associated with employability (Becker, 1993), and positive associations have, in turn, been found between volunteering and human capital. Volunteering has been linked with the development (and/or maintenance) of job specific or 'hard' skills (Hirst, 2001; Cook and Jackson, 2006), soft skills such as team work and communication (Newton et al, 2011), and 'civic' skills such as fundraising (Musick and Wilson, 2008 quoting a study by Verba et al. 1995). Young people in particular are likely to report skills-related gains: in one survey, 80 per cent of 25-34 year olds said that the chance to learn new skills was an important benefit of volunteering, compared to 61 per cent of all the volunteers surveyed (Low et al, 2007). More generally, volunteering may also help with the development of 'work attitudes' and behaviours (Krahn et al., 2002), and also in the growth in confidence and self-esteem (Low et al., 2007; Williams et al., 2001; Newton et al., 2011). 
Social capital - the resources that accrue through membership of durable networks ${ }^{3}-$ is also positively related to employability (see for example Granovetter, 1983), and positive associations have been found between volunteering and social capital (see for example Muthuri et al., 2006; Wilkinson and Bittman, 2002; Wollebaek and Selle, 2002). As Musick and Wilson (2008: 489) note: 'volunteering builds social networks, which makes it easier to get a good job' (see also Wuthnow, 1998).

Few studies have explored more directly the link between volunteering and employment outcomes. A few case studies have been conducted within specific volunteer-involving organisations or initiatives, giving further weight to the positive association argument. Conservation Volunteers (2004) reported that 45 per cent of its Key Volunteers went on to find work in the environment sector, 16 per cent within the organisation itself (see also Cook and Jackson, 2006, for findings amongst VSO volunteers). Research into Local Exchange and Trading Schemes (LETS) - participants within which are generally volunteers - concluded that LETS indirectly provide a bridge into employment by improving employability, although they were most effective in terms of building business for the self-employed and were hampered by the existence of barriers for unemployed people participating in LETS (Williams et al., 2001). Most of these studies, however, are small scale, do not use comparison or control groups, and are unlikely to be representative of the UK's population.

Various other studies have reported employability/career related benefits of volunteering for certain groups of the population, including: refugees (Stopforth, 2001); gap-year participants (Jones, 2004); and young people (Newton et al., 2011. Many of these studies, however, rely on self-reported measures of impact (e.g. volunteers say they feel more employable and have gained skills or employment through their volunteering) and/or on small sample sizes.

Research among disabled people presents a more complex picture. Logistic regression modelling within an evaluation of the UK's New Deal for Disabled People Personal Advisory Service $^{4}$ pilot projects, found that those who were not volunteering while claiming

\footnotetext{
${ }^{3}$ Needless to say, social capital is a highly contested term with no one accepted definition. This article is not the place to enter those debates.

${ }^{4}$ The New Deal for Disabled People was a joint initiative of the Department for Social Security, the Department for Education and Employment, Employment Services and the Benefit Agencies. The scheme consisted to two main elements: the Personal Advisor Service and the Innovative Schemes. The Personal Advisors Service was targeted at people with long term illnesses or impairments, aiming to help those who wanted to work to do so
} 
incapacity-related benefits ${ }^{5}$ were twice as likely (in terms of probability) to have done paid work since meeting with a Personal Advisor compared to those who had been volunteering (Loumidis et al., 2001; see also Corden and Sainsbury, 2001; Corden, 2002).

There are very few cross-sectional or longitudinal studies which have directly explored the link between volunteering and employability outcomes. One large-scale study of volunteering and employment was undertaken by Gay and Hatch in 1983, at a time when unemployment levels had risen to 1.5 million leading to considerable policy interest in the role of volunteering in reducing that figure. The research found that volunteering levels among unemployed people were low and that while unemployed volunteers felt that their participation had improved their self-confidence, filled time and gave them an opportunity to use their skills, very seldom was the link between volunteering and employability or employment made (Gay and Hatch, 1983; Gay, 1998).

A Department for Education and Skills commissioned study in 2001 explored the links between volunteering and employability for recipients of Jobseekers Allowance (JSA - a State benefit paid to unemployed people while they look for work) (Hirst, 2001). Despite finding that 88 per cent of those still looking for work and 41 per cent of those already in work felt that volunteering would/had helped them find a job, JSA claimants who had volunteered were not more likely overall to move off JSA than those who did not volunteer. Volunteering did have a marginally positive impact on employability for some people but only those people whose motive for volunteering was employment related. Indeed, overall, volunteers tended to have a longer duration of unemployment than non-volunteers (McKay et al., 1999).

In a comparative study of volunteering and employability, Strauß (2009) analysed data from the British Household Panel Survey and the German Socio-Economic Household Survey. The study found a positive effect of volunteering (measured through a question on participation within voluntary associations) on re-employment chances among unemployed people, particularly among young British men. There was less of an association in Germany.

and to help those already in work to remain in employment and to extend the range of services available to them. The pilot programme was launched in 1998 in six areas, extending to another six areas in 1999.

${ }^{5}$ State benefits paid to people who are below the state pension age and cannot work because of a disability or illness. 
There is, therefore, a limited amount of existing evidence on the impact of volunteering on moves from being out of work into work. As Hillage and Pollard (1998) remind us, however, employability is not only about moving into employment; it also relates to job retention and progression. Here we find even less evidence of the role of volunteering. Through a survey with a representative sample of 8,168 French households, public sector volunteers were found to receive a positive wage premium (equal to $5.5 \%$ ), while in the private sector the premium was found to be negative (equal to $-1.7 \%$ ) (Prouteau and Wolff, 2006). Overall, the study concluded that there was no difference in hourly wages between volunteers and nonvolunteers. In a Canadian study, Day and Devlin (1998) had earlier found that volunteers' incomes were on average 7 per cent higher than those of non-volunteers, although it was not possible to infer any causal connection between volunteering and the wage premium (Prouteau and Wolff, 2006). Studies of mature women (Statham and Rhoton, 1985) and younger women (Wilson and Musick, 2003) in America found that volunteers were (at best) no better off in terms of income than non-volunteers, but volunteering did affect job status (Musick and Wilson, 2008).

Overall, as others have noted, it is hard to find statistical evidence of the link between volunteering and employability outcomes (Prouteau and Wolff, 2006; Holdsworth and Quinn, 2010; Smith, 2010; Corden and Ellis, 2004). Many studies fail to establish a direct link. Where a link has been suggested, various factors can be identified that influence its intensity, including: volunteer demographics (Strauß, 2009); amount of volunteering undertaken (Hirst, 2001; Stratham and Rhoton, 1985); the reason for getting involved (e.g. whether volunteering is part of an employment strategy); the nature of the role; the variety of tasks and the contact with others when delivering the task (Hirst, 2001); the closeness of fit between the volunteering role and the employment role being sought; and the nature and quality of support provided to the volunteer (Gay and Hatch, 1983; Hirst, 2001). Overall the picture is mixed and somewhat confusing suggesting the relationship is far from straightforward, and leaving a considerable gap in our understanding of the links between volunteering, employability and employment.

Using longitudinal data from the British Household Panel Survey (BHPS), we set out to address this gap by testing the effect of volunteering on employability outcomes specifically: moves from being out of work into work; employment retention; and on progression in terms of wage levels. 


\section{Methods and data}

\section{The British Household Panel Survey (BHPS)}

The BHPS is a panel study with data available from 1991 through to 2008/09, among individuals living in private households across the UK. The survey includes questions on standard human capital and demographic variables, including employment status ${ }^{6}$, education, occupation, age, gender, earnings and hours worked.

Since 1998 the survey has included, on a biennial basis, a question on voluntary work and another on participating in local groups (see Box 1). The questions are narrow. Respondents are asked how frequently they do unpaid voluntary work and how often they attend meetings of local groups - at least once a week; at least once a month; several times a year; once a year or less; never or almost never.

\section{Box 1: BHPS questions on volunteering}

We are interested in the things people do in their leisure time, I'm going to read out a list of some leisure activities. Please look at the card and tell me how frequently you do each one.

Attend meetings for local groups/voluntary organisations?

Do unpaid voluntary work?

Doing unpaid voluntary work is our focus of interest, as it seems to relate most closely to the concept of (formal) volunteering in England. As we discuss below, however, we recognise the limitations of the question.

We begin with some exploratory analysis of the most recently available data - that for 2008/09. Table 1 shows that 23 per cent of people did some unpaid voluntary work, while 27

\footnotetext{
${ }^{6}$ Labour market status is measured on the basis of respondents indicating a reply to a set list, with the prompt, "Please look at this card and tell me which best describes your current situation?" with codes: Self employed / In paid employment (full or part-time) / Unemployed / Retired from paid work altogether / On maternity leave/ Looking after family or home / Full-time student / Long term sick or disabled / On a government training scheme / Something else (PLEASE GIVE DETAILS)
} 
per cent participated in local groups. These rates are lower than found in the Citizenship Survey referred to above, a reflection of the narrow scope of the BHPS volunteering question (see Staetsky and Mohan, 2011; Lynn, 1997; Lyons et al, 1998; Hall, 2001 for a discussion on the significance of how volunteering is measured). Across time, however, 37 per cent of the panel had volunteered at some point (among those appearing in at least one wave where the volunteering question was included).

\section{[Table 1 about here]}

The second panel of Table 1 shows the proportions of different groups who were taking part in voluntary activities at least monthly. They confirm the relatively low levels of participation among those unemployed or disabled, with higher participation rates for those in paid work including the self-employed. Among those in employment, volunteering levels were highest among those who worked for non-profit organisations and lowest among those who worked in the private sector (results not shown in tables).

The volunteers were also more likely to be older than younger; and those with degreelevel qualifications and above were more likely to volunteer than those with low or no qualifications. There was also something of a social class gradient, with professional and managerial classes the most likely to volunteer. Women were more likely to volunteer than men. This demographic profile of volunteers is similar to that found in other surveys of volunteering in the UK (Low et al., 2007; CLG, 2011).

\section{Panel analysis of the British Household Panel Survey}

We created a longitudinal dataset taking the seven BHPS waves in which the volunteering question was asked. It contained over 92,000 observations (25,000 different individuals observed for an average of close to four of the relevant waves of the survey). We use data on the current employment situation and the employment situation from one year before, and consider how the association between the two is mediated by reports of volunteering.

We ran a series of regression models of the relationship between volunteering and employability. While the focus of our analysis, and of government policy, has been on the effect of volunteering on moves into work, we were prompted by Hillage and Pollard (1998) to develop three separate models of employability: moving into work; remaining in work; and 
progression in the form of earnings levels. We explored the influence of frequency of volunteering (the only detail available within BHPS on the volunteering activity) on the employability outcomes, alongside age (given the policy focus on young people using volunteering as a route to employment and the effect of age on career-related motivations) and reasons for not being in employment (assuming that the desire and indeed ability to move into work would vary across groups).

Each model controlled for education, and several socio-economic characteristics. These are included owing to their known associations with human capital and hence with moving into paid work. We include them to account for most of the differences in rates of taking paid jobs, and hence to more accurately identify any effects from voluntary activity. Time and regional dummy variables were included to control for any variations relating to region (e.g. more returning to work in London) or over time (good and bad years for growth) which, whilst potentially interesting in themselves, are not a central part of our analysis here.

To examine the effects of volunteering on entering employment, we carried out a series of logit regression models, where $y_{i, t}$ takes the value 1 if from period $t-1$ to period $\mathrm{t}$ the individual has entered employment, and 0 otherwise.

$$
\begin{gathered}
\mathbf{y}_{\mathrm{i}, \mathrm{t}}=\left\{\begin{array}{l}
1 \\
0
\end{array}\right. \\
\operatorname{Pr}\left(\mathbf{y}_{\mathrm{i}, \mathrm{t}}=\mathbf{1} \mid \mathbf{x}\right)=\frac{\mathbf{e}^{\mathrm{x} / \boldsymbol{\beta}}}{1-\mathrm{e}^{\mathrm{x} / \boldsymbol{\beta}}}
\end{gathered}
$$

In this equation $x$ is the set of explanatory variables that capture individual socio-economic characteristics, time and regional dummy variables (see above).

The BHPS, and indeed our analysis, have important limitations, which we discuss below. Of particular note here, we measure current labour status at each annual interview, whilst volunteering is measured biennially and responses focus on frequency of volunteering over a time period which is not explicitly specified. It is not therefore possible to accurately assess the time period between volunteering behaviour and movements into work.

For retention we use the same approach to explore the odds of exiting employment, but with a starting point of those in work, rather than those not in work, so $y_{i, t}$ takes the value 1 if 
from period $t-1$ to period the individual has exited employment, and 0 if they are still in employment.

For wage rates we estimated a standard wage equation using OLS, for the log wage received by individual $i$, at time $t$,

$$
\begin{aligned}
\ln \left(\mathbf{w}_{\mathbf{i}, \mathrm{t}}\right)=\alpha_{0} & +\alpha_{1} V O L+\alpha_{2} G E N+\alpha_{3} A G E+\alpha_{4} A G E^{2}+\alpha_{5} M A R_{S T}+\alpha_{6} \mathrm{JOBSEC} \\
& +\alpha_{7} \text { EMPTIPE }+\alpha_{8} \text { EDU }+\alpha_{9} \text { WAVE }+\mu_{\mathrm{i}}+\epsilon_{\mathrm{i}, \mathrm{t}}
\end{aligned}
$$

Where VOL indicates extent of volunteering, and the other variables refer to personal and job-related characteristics (with an individual specific term $\mu_{\mathrm{i}}$ that may be estimated using either fixed or random effects). We use each category of the volunteering question, to consider the effect of different frequencies of volunteering.

\section{Results}

\section{Entry into work}

Having controlled for differences in education we found a statistically significant, but weak, effect of volunteering on entry into work. The frequency of volunteering affected the results (see table 2). The table shows the odds of different groups moving into paid work on an annual basis; a positive value shows a higher likelihood of moving into work than the base group, and a negative value a reduced likelihood. So, for instance, the ' 0.247 ' relating to doing voluntary work at least once a month indicates a higher rate of returning to work for this group than for the baseline group of people who never volunteered. In contrast, the '0.235 ' relating to doing voluntary work at least once a week indicates a lower rate of returning to work for this group compared to those who never volunteered.

In summary, volunteering on a monthly basis had a positive effect on the chances of people not in work one year moving into paid employment the next year. However, those volunteering on a weekly basis or a yearly basis had lower than average chances of moving into paid work. More generally, the table also suggests a lower rate of movement into work for women than men, but the difference was too small to be statistically significant; those who were married tended to return to work quicker than other groups; people who were longterm sick or disabled had a much lower rate of returning to work than the baseline group of unemployed people. 
Within the sample we found the effect of volunteering on entry into work varied according to different demographic characteristics. For example, the effects varied according to age (see table 2). Volunteering had a positive effect on the chances of moving into work for people aged 45-60 years old when undertaken on a monthly or slightly less frequent basis. We found no positive effect of volunteering on young people's (16-25 year olds) moves into employment, no matter how much they did: infrequent volunteering had no effect; regular (monthly or weekly) volunteering had a negative effect. Among 26-44 year olds, volunteering had very little effect - either positive or negative - on the chances of moving into employment.

[Table 2 about here]

The effects of volunteering on moving into work also varied according to the reason why people were economically inactive - whether they were unemployed, undertaking family care, students or disabled (see table 3). This is not surprising: a student may be volunteering but with no expectation of looking for paid work until more than a year later, whilst someone unemployed may be hoping to find paid work within weeks. A parent caring for a young child may be mindful of acquiring new skills and experience through volunteering, but still see the transition to employment as something very much for the longer term.

For unemployed people, volunteering several times a year had a positive effect on the changes of moving into employment, while volunteering on a weekly basis had a negative effect. Monthly and yearly volunteering had no significant effect. For those out of work with family caring responsibilities, volunteering on a monthly basis had a positive effect, taking part on a weekly basis had a negative effect. Among students, volunteering on a monthly basis had no significant effect, while any more or less volunteering had a negative effect. Among disabled people, volunteering several times a year was found to have a positive effect on the move into employment, while doing more or less than this had little effect either way.

[Table 3 about here]

Overall then, our analysis suggests that some volunteering can have a positive effect on the likelihood of people moving into employment, but it depends on who you are, why you 
are out of work, and on how much volunteering you do. It suggests that doing 'too much' volunteering (i.e. on a weekly or more frequent basis) may have a negative effect, particularly among young people and/or students.

\section{Retention}

Alongside exploring the impact of volunteering on the move into employment, we explored its impact on job retention: remaining in employment rather than leaving a job. Across the whole sample, we found no particularly strong effects of volunteering on job retention, although results varied according to frequency of involvement, age and other demographic factors (see table 4).

[Table 4 about here]

Volunteering several times a year had a (significant but weak) positive effect on job retention for the sample as a whole; whereas more or less frequent volunteering had no significant effect. When exploring the results across age groups, we found that for those aged 26-44 years old volunteering several times a year had a positive effect on retention (more or less frequent volunteering had no effect), whereas volunteering had no effect on employment retention amongst those aged 45-60 years old, no matter how frequently they participated. Amongst 16-24 year olds, while volunteering once a year or less was found to have a positive effect on job retention, volunteering at least once a month had a negative effect - although volunteering weekly or several times a year had no effect (see Table 4). 


\section{Progression}

As an indicator of progression within the labour market, we also explored the effect of volunteering on wage rates. Our analysis suggests that, if anything, volunteering has a negative effect on wage levels (see table 5). We present results both from a fixed-effects specification (effectively, separate intercept terms for each respondent) and from a randomeffects approach (intercepts based on a distribution). This is assessing the effect of a change in the amount of voluntary work.

[Table 5 about here]

Frequent (weekly) volunteering and infrequent (several times or once a year) volunteering had a negative effect on wage rates, while the effect of monthly volunteering was not significant. According to this analysis volunteering doesn't appear to help people get on in their career, in terms of earning more, and if anything has the opposite effect.

\section{Discussion and conclusion}

Our analysis of the BHPS suggests that volunteering has a weak effect on employability outcomes, in terms of moves into employment, job retention and progression. Volunteering can assist the move into employment, but seemingly only if done at the right frequency (not too regularly, not too infrequently) and for certain people (older people and those with family caring responsibilities). For young people and students in particular, and if done too frequently, our analysis suggests volunteering can have a negative effect on the move into employment and on earnings.

We are left with a bit of a puzzle. Policy and practice discourses have put great store on the link between volunteering and employability. Evidence to date has largely substantiated these claims through reporting that volunteers felt more employable, that employers viewed volunteering on a CV positively, and that volunteering positively affects relevant human and social capital indicators which in turn have been associated with individual employability gains. Our findings run somewhat contrary to this. The mixed results reflect the limitations of the data and our analysis for answering the question of the extent to which volunteering enhances employability: the BHPS questions are narrow, the two variable of employability and volunteering are complex; and the links between them are likely to be mediated by numerous other influences. Below we expand upon these limitations and offer other ideas 
which may go some way towards an explanation for our findings and the variations we find with existing evidence and policy rhetoric.

\section{Survey and analysis limitations}

We are not aware of any other research in the UK which has used such a large dataset in the exploration of the link between volunteering and employability. Size is not, however, everything and the BHPS has some specific limitations for this analysis. The volunteering question is very narrow, limiting the number and potentially the diversity of people who identify themselves as volunteers and the level of analysis that can be conducted. Strauß's (2009) analysis of volunteering and employability, which made use of BHPS question on participation in associations, found that volunteering had a positive effect on employment, indicating the significant difference that the way we measure volunteering, even within one survey, can make.

We also know nothing about the nature of volunteering that was being undertaken by BHPS respondents, beyond how frequently it was done - and we have demonstrated above that this influences the effect of volunteering on moves into employment. From previous studies we might expect that the different forms that volunteering takes - the nature of the volunteering role; the intensity and duration of involvement in individual and multiple roles; the different motivations that volunteers bring to the role (Hirst, 2001); and the different support structures that are in place for volunteers may qualify the effect that volunteering has on employability (Rochester, 2009). The BHPS does not provide us with any insight into these different aspects of the volunteer role and experience and this creates a major limitation.

Further, the time period within which the BHPS data was gathered may be influencing the results, as might the treatment of time within our analysis. The data was collected from 19962008 at a time when there was considerable policy interest in the link between volunteering and employability, but before which there was such pressure on the labour market through high levels of unemployment and declining job opportunities. The timing of the survey may also have specific implications for the results found for students. The negative effect of volunteering on employability found here for students (and young people) is particularly surprising, given the weight of counter evidence/argument, but this may in part be explained 
by the design of the survey and our analysis as it may be that we are picking up students in their first or second year of study who we would not expect to have moved into employment the following year (our analysis does not directly measure year of study).

Indeed, our analysis has included all economically inactive people - regardless of whether or not they are actively looking or immediately available for work - which is also likely to affect the results. However, when we broke down our analysis for different categories of economic inactivity, as in table 3, volunteering did not appear to have a particularly strong or more positive impact on moves into employment for those who were classified as unemployed (and therefore presumably actively looking and available for work) compared to those who were classified as disabled or undertaking family care (and therefore presumably less likely to be looking and available for work).

Importantly, our analysis has explored the effects of volunteering on the moves into (and out of) employment from one year to the next. This is another important limitation. We might find different results if we explored longer term effects. Research from elsewhere for example, suggests that volunteering may have a positive effect on educational outcomes, which in turn effects employment (see Musick and Wilson, 2008 for summary).

\section{Neglect of the demand side of employability}

The concept of employability found within policsy discourses has been subject to considerable critique for its over-emphasis on individuals' skills and abilities - the supply side of the labour market (see for example Peck and Theodore, 2000; Wilton, 2011; McQuaid and Lindsay, 2005). Employability-related policies generally locate both the problem and the solution in the supply side of the labour market, which may be insufficient to tackle unemployment as they make little impact on the structural causes of unequal labour market opportunities (Peck and Theodore, 2000); they do not address the disadvantages that certain groups face in the labour market (Wilton, 2011).

Our findings can be seen to add weight to these critiques. Although not possible to test within the BHPS (another limitation to the survey), it may be possible that (as other studies have suggested - see above) volunteering adds considerably to the supply side - to individual and personal factors - by building (at least some) volunteers' skills, confidence, work 
practices, and social contacts - but, as it does little to address any limits within the demand side of the labour market, any gains are ineffective. Structural barriers which exist for those looking to move from unemployment into employment, or to stay or progress within existing employment, continue whether or not volunteering has enhanced individual employability factors.

Indeed, the demographic profile of volunteers suggests that volunteering itself is subject to the same structural barriers to participation as found in the labour market (IVR, 2004). Rather than opening up access to labour market participation, volunteering may be reinforcing the existing barriers by itself being an exclusive activity.

\section{Volunteering is about more than employability}

Despite the attention that has been paid to the potential link between volunteering and employability, a minority of volunteers report being motivated by it or recognise it as an important benefit (see for example Low et al, 2007). For many participants volunteering is disconnected from their paid work. As others have argued, rather than being a route into work volunteering may act more as an alternative to work, or as additional to work (Corden and Ellis, 2004; Hardill and Baines, 2008; IVR, 2004; Perkins and Rinaldi, 2002). Indeed, treating volunteering as work is only one way to conceptualise it: it can also be conceptualised as a: leisure, service, or caring activity (Rochester et al., 2010). Conceptualising volunteering as something other than work shifts the focus from employability-related outcomes to other impacts, such as individual sociability, enjoyment and well-being, and social capital gains.

Not only are many volunteers uninterested in possible employability gains from volunteering, they may also be different types of people or have different value sets from non-volunteers and this may influence their wider approach and attitude to work. One could hypothesise, for example, that volunteers are less likely to be driven by career progression and financial reward, and this may be influencing the results (a selection bias, in effect) (see Musick and Wilson 2008 for a similar argument). 


\section{Taking stock and moving forwards}

Policy and practice discourses are awash with stories of individual's gaining employment through their volunteering experience. We do not doubt the validity of these testimonies. Our longitudinal analysis has found that volunteering can have a positive effect on the likelihood of people moving into employment, and in some cases on employment retention. Whether or not it does, however, depends on who you are, why you are out of work, and how frequently you participate. Our analysis of the BHPS data suggests that volunteering on a monthly basis may have a positive effect on the chances of people who are not in work one year moving into work the next, but volunteering on a more or less frequent basis may reduce or even reverse the effect. While policy discourses have particularly focused on the potential of volunteering to act as a route into employment among young people, our analysis has failed to substantiate this claim. Overall, volunteering (as measured in the BHPS) does not appear to have as strong or as positive an effect on employability outcomes - on moves into employment, on retention and progression - as suggested in both policy rhetoric and in some previous research.

Survey and analysis limitations go some way towards providing an explanation for the gap between the rhetoric and our findings. There is certainly more that could be done with the BHPS to interrogate the relationship further - for example, by looking at the influence of volunteering over a longer time period. There is also a need to look to new sources of evidence which would allow for a more detailed analysis of the influence of volunteer motivation, and the nature of the volunteering role on employability outcomes.

At least as convincing, however, are the arguments for the need for both a broader understanding of employability and of volunteering. While volunteering may enhance an individual's skills, confidence and self-esteem and may help to build their CV and contacts, it is unlikely to affect the demand side of the labour market and therefore any employability gains are muted. Volunteering alone cannot tackle the structural inequalities which underlie the labour market - indeed volunteering is itself subject to those same inequalities - reducing its effect on employment outcomes.

In unison with others, we suggest that volunteering may be better thought of as an alternative to employment, or rather to be conceptualised in ways other than as a form of work or solely as a personal investment activity. Employment related motivations are not the 
most significant triggers for many volunteers. While volunteering can enhance employability outcomes for some individuals in some contexts, the true value of volunteering, arguably, lies elsewhere.

\section{Acknowledgements}

We would like to thank two anonymous reviewers and the editor for their helpful and considered comments. The support of the Economic and Social Research Council (ESRC), the Office for Civil Society (OCS) and the Barrow Cadbury UK Trust is gratefully acknowledged. The work was part of the programme of the joint ESRC, OCS, Barrow Cadbury Third Sector Research Centre.

\section{References}

Becker, G. (1962) 'Investment in human capital: A theoretical analysis' Journal of Political Economy 70(5): 9-49.

Clary, E. and Snyder, M. (1991) 'A functional analysis of altruism and prosocial behaviour: The case of volunteerism' pp.119-148 in Clark, M. (ed) Review of personality and social psychology: Vol 12, Newbury Park, California: Sage

Clary, E., Snyder, M. and Ridge, R. (1992) 'Volunteers' motivations: A functional strategy for recruitment, placement and retention of volunteers' Nonprofit Management and Leadership 2(4): 333-350.

CLG (Communities and Local Government) (2011) Citizenship Survey: 2010-11 (April 2010 - March 2011), England. Cohesion Research Statistical Release Number 16, London: CLG, accessed from http://www.communities.gov.uk/documents/statistics/pdf/1992885.pdf.

Cook, P. and Jackson, N. (2006) Valuing volunteering: A route to professional development: Views from VSO volunteers and managers. London: Chartered Management Institute.

Corden, A. (2002) 'Voluntary work: A bridge from long-term incapacity to paid work?', Voluntary Action, 4 (2): 31-47.

Corden, A. and Ellis, A. (2004) 'Volunteering and employability: Exploring the link for incapacity benefits recipients', Benefits, 12 (2): 112-118.

Corden, A. and Sainsbury, R. (2001) Incapacity benefits and work incentives. DSS Research Report 141, Leeds: Corporate Document Services.

Davis Smith, J., Ellis, A. and Howlett, S. (2002) Millennium Volunteers programme: UK wide evaluation. Sheffield: Department for Education and Skills. 
Day, K. and Devlin, A. (1998) 'The payoff to work without pay: Volunteer work as an investment in human capital', The Canadian Journal of Economics, 31 (5): 1179-91.

Department for Work and Pensions (2012) Get Britain working: Work together, accessed on 25.06.12 from http://www.dwp.gov.uk/docs/work-together-lft.pdf.

DirectGov (2012) Volunteering while looking for work. Accessed on 25.06.12 http://www.direct.gov.uk/en/employment/jobseekers/lookingforwork/dg_10033053.

Gay, P. (1998) 'Getting into work: Volunteering for employability', Voluntary Action, 1 (1): 55-67.

Gay, P. and Hatch, S. (1983) Voluntary work and unemployment. London: Policy Studies Institute.

Granovetter, M. (1983). The strength of weak ties: A network theory revisited.Sociological theory, 1(1): 201-233.

Hall, M., Knighton, T., Reed, P., Bussiere, P. Macrae, D. and Bowen, P. (1998) Caring Canadians, involved citizens: Highlights from the 2000 National Survey of Giving, Volunteering and Participation, Ottawa: Statistics Canada.

Hall, M. (2001) 'Measurement issues in surveys of giving and volunteering and strategies applied in the design of Canada's National Survey of Giving, Volunteering and Participating', Non-Profit and Voluntary Sector Quarterly, 30 (3): 515-26.

Hardill, I. and Baines, S. (2008) 'At least I can do something: The work of volunteering in a community beset by worklessness', Social Policy and Society, 7 (3): 307-17.

Hillage, J. and Pollard, E. (1998) Employability: Developing a framework for policy analysis. Research Brief 85, London: Department for Education and Employment.

Hirst, A. (2001) Links between volunteering and employability. Research Report RR309, Department for Education and Skills, accessed on 28/01/09 from: http://www.dcsf.gov.uk/research/data/uploadfiles/RR309.PDF

Holdsworth, C. and Quinn, J. (2010) 'Student volunteering in English higher education', Studies in Higher Education, 35 (1): 113-27.

IVR (Institute for Volunteering Research) (2004) Volunteering for all? Exploring the link between volunteering and social exclusion. London: IVR.

Jones, A. (2004) Review of gap year provision. Research Report 555, London: Department for Education and Skills.

Krahn, H., Lowe, G. and Lehmann, W. (2002) 'Acquisition of employability skills by high school students', Canadian Public Policy, 28 (2): 275-96. 
Loumidis, J., Stafford, B., Youngs, R., Green, A., Arthur, S., Legard, R., Lessof, C., Lewis, J., Corden, A., Thornton, P. and Sainsbury, R. (2001) Evaluation of the New Deal for Disabled People personal advisers service pilot. DSS Research Report No 144, Leeds: Corporate Document Service.

Low, N., Butt, S., Ellis Paine, A. and Davis Smith, J. (2007) Helping out: A national survey of volunteering and charitable giving. London: Cabinet Office.

Lynn, P. (1997) ‘Measuring Voluntary Activity’, Non-Profit Studies, 1 (2): 1-11.

Lyons, M., Wijkstrom, P. and Clary, G. (1998) 'Comparative studies of volunteering: What is being studied', Voluntary Action, 1 (1): 45-54.

McKay, S., Smith, A., Youngs, R. and Walker, R. (1999) Unemployment and job-seeking after the introduction of Jobseekers Allowance. Leeds: CDS.

McQuaid, R. and Lindsay, C. (2005) 'The concept of employability', Urban Studies, 42 (2): 197-219.

Musick, M. and Wilson, J. (2008) Volunteers: A social profile, Bloomington and Indiana: Indiana University Press.

Muthuri, J., Moon, J. and Matten, D. (2006) Employee volunteering and the creation of social capital. ICCSR Research Paper Series No. 34-2006.

Newton, B., Oakley, J. and Pollard, E. (2011) Volunteering: Supporting transitions. v: The National Volunteering Service.

Office for National Statistics (2013) Labour market statistics: August 2013. London: ONS, accessed from http://www.ons.gov.uk/ons/rel/lms/labour-market-statistics/august2013/index.html

Peck, J. and Theodore, N. (2000) 'Beyond employability', Cambridge Journal of Economics 24: 729-49.

Perkins, R. and Rinaldi, M. (2002) 'Unemployment rates among patients with long-term mental health problems: A decade of rising unemployment', The Psychiatrist, 26 (8): 29598.

Prouteau, L. and Wolff, F-C. (2006) 'Does volunteer work pay off in the labour market?', The Journal of Socio-Economics, 35 (6): 992-1013

Rochester, C. (2009) A gateway to work: The role of volunteer centres in supporting the link between volunteering and employment. London: IVR.

Rochester, C., Ellis Paine, A. and Howlett, S. (2010) Volunteering and society in the $21^{\text {st }}$

Smith, V. (2010) 'Review article: Enhancing employability: Human, cultural and social capital in an ear of turbulent unpredictability', Human Relations, 63 (2): 279-303. 
Staetsky, L. and Mohan, J. (2011) Individual voluntary participation in the United Kingdom: An overview of survey information, This Sector Research Centre Working Paper 6, Birmingham: Third Sector Research Centre.

Stopforth, S. (2001) 'The effects of volunteering on refugees' prospects of getting paid work', Voluntary Action, 4 (1): 11-27.

Statham, A. and Rhoton, P. (1985) The volunteer work of mature and young women: 19741981, Columbus: Centre for Human Resource Research, Ohio State University.

Strauß, S. (2009) Ehrenamt in Deutschland und Großbritannien - Sprungbrett zurück auf den Arbeitsmarkt? (Volunteering in Germany and Great Britain - Spring-board Back to the Labour Market?), KZfSS Kölner Zeitschrift für Soziologie und Sozialpsychologie, 61 (4): 647-70.

The Conversation Volunteers (2004) Key Volunteers webpage http://www.tcv.org.uk/volunteering/get-more-involved/key-volunteers.

Timebank (2004) Employer attitude survey. London: Timebank.

v (2008) Youth volunteering: Attitudes and perceptions. London: v.

v,Verba, S., Lehman Schlozman, K. and Brady, H. (1995) Voice and equality: Civic voluntarism in American politics, Cambridge: Harvard University Press.

Williams, C., Aldridge, T., Lee, R., Leyshon, A., Thrift, N. and Tooke, J. (2001) 'Bridges into work? An evaluation of Local Exchange and Trading Schemes (LETS)', Policy Studies, 22 (2): 119-32.

Wilkinson, J. and Bittman, M. (2002) Volunteering: The human face of democracy. Social Policy Research Centre Discussion Paper No. 114, http://www.sprc.unsw.edu.au/dp/DP114.pdf.

Wilton, N. (2011) 'Do employability skills really matter in the UK graduate labour market? The case of business and management graduates', Work, Employment and Society, 25 (1): 85-100.

Wollebaek, D. and Selle, P. (2002) 'Does participation in voluntary associations contribute to social capital? The impact of intensity, scope and type', Nonprofit and Voluntary Sector Quarterly, 31: 32-61.

Wuthnow, R. (1998) Loose Connections, Cambridge: Havard University Press.

Yarwood, R. (2005) 'Geography, citizenship and volunteering: Some uses of the Higher Education Active Community Fund', Journal of Geography in Higher Education, 29 (2): 335-68. 
Zimmeck, M. and Rochester, C. (2011) 'Something old, something new, something borrowed, something blue: Governments' approach to volunteering in England since 1997'. Paper presented at Conference of Philanthropy Studies, European University of Voluntary Service, Basel. 